\title{
Da Nacionalidade e da Cidadania em Face da Nova Constituição*
}

\author{
Washington de Barros Monteiro \\ Catedrático de Direito Civil na Faculaade de \\ Direito da Universidade de São Paulo.
}

\begin{abstract}
SUumário: 1. Situação do estrangeiro através dos tempos. 2. Conceito de nação e de nacional. 3. Critérios legais para distinguir nacionais e estrangeiros. 4. Brasileiros natos. 5. Brasileiros naturalizados. 6. Nacionais e estrangeiros perante o ordenamento jurídico pátrio. 7. Perda da nacionalidade brasileira. 8. Princípios gerais sôbre nacionalidade. 9. Direito de cidadania. 10 Conclusão.
\end{abstract}

1. A situação do estrangeiro, no país em que se encontre, quer temporàriamente, quer em caráter definitivo, é profundamente diversa da que desfrutava não só nos primórdios da civilização como até mesmo em épocas mais próximas.

O direito primitivo considerava-o ora como escravo ora como inimigo, não the sendo lícito ombrear-se com o nacional, colocado sempre em posição preeminente.

Assim, na Índia, nem siquer figurava êle entre as múltiplas castas. Não passava de um verdadeiro pária, à margem da sociedade, classificado abaixo de certos irracionais e privado de certos direitos religiosos e sociais.

No antigo Egito, os estrangeiros foram empregados na construção das pirâmides, nas quais se insculpia a inscri-

* Palestra proferida na sessão do dia 11 de maio de 1967, do Conselho Técnico de Economia, Sociologia e Política, órgão da Federação do Comércio do Estado de São Paulo. 
ção orgulhosa: "neste monumento nenhum homem do país trabalhou".

Entre os gregos ocorreu a conhecida discriminação: isóteles, metecos e bárbaros. Se os primeiros gozavam de déterminados direitos e garantias, aos segundos já se impunham maiores restrições, enquanto os terceiros não faziam jus à proteção alguma, permanecendo, destarte, pràticamente, fora da civilização, totalmente alheios aos seus benefícios.

Aliás, até mesmo os filósofos mais moderados refletiam êsse estado de espírito. Platão dividia a humanidade em gregos e bárbaros. Aristóteles, a seu turno, ensinava que os bárbaros, por sua própria natureza, se destinavam a ser escravos dos gregos, acrescentando ser legítimo o emprêgo de qualquer meio tendente a promover tal escravização.

O próprio direito consagrou a separação, bastante nítida no direito romano: o estrangeiro achava-se excluido do gôzo do jus civile, fruindo apenas dos direitos outorgados pelo jus gentium. Só ao tempo de Caracalla, com a famosa constituição do ano 212 e que vem a ser o ponto terminal de longa evolução histórica, se estendeu indistintamente a cidadania romana a quase todos os súditos do império: in orbe romano qui sunt, ex constiiutione imperatoris Antonini cives romani effecti sunt.

A condição do estrangeiro, para servir-mo-nos de imagem de Ihering, assemelhava-se à de uma fera, a quem se dava caça, onde quer que se encontrasse. A negação de qualquer direito ao alienígena, nos albores da civilização, parecia tão justa, tão natural, ajuntava o mesmo IHERING, como, em nossos dias, a capacidade jurídica do homem, como tal considerado.

Hostes - o inimigo, eis a expressão que, no primitivo direito romano, caracterizava a posição do estrangeiro. Só muito tempo depois é que outro vocábulo surgiu em substituição a revelar maior condescendência e humanidade peregrinus. 
No velho direito germânico subsistia também idêntica prevenção, que, a bem dizer, era uma constante na mentalidade dos povos primitivos. $O$ estrangeiro era ali denominado Wargangus, isto é, vagabundo e não tinha direito algum. Verdadeiramente falando, jazia fora da lei, a menos que houvesse, um homem livre, que, por êle, se responsabilizasse.

Por igual no antigo direito inglês era havido como wretch (miserável) e para ressaltar-se apenas uma das inúmeras limitações impostas ao estrangeiro bastaria trazer à colação, nesta oportunidade, o droit d'aubaine (diritto di albinaggio), em virtude do qual, no período medieval, se permitia ao soberano apoderar-se de bens deixados por estrangeiro e falecido sem descendência com a nacionalidade do país.

Nesses tempos de ferro, em que não se honra a humanidade, deparamos, todavia, às vêzes, mão amiga estendida em direção ao estrangeiro.

Assim, no Levítico (XXIV - 22) encontramos esta passagem expressiva: "Quando, pois, ceifardes a seara dos vossos campos, não a cortareis até a terra nem enfeixareis as espigas que ficarem; mas, deixá-las-eis para os pobres e para os forasteiros" Da mesma forma, no Deuteronômio (I-16), há esta apóstrofe, impregnada de intensa sabedoria: "Ouvi-os e julgai segundo a justiça, quer se trate de um cidadão, quer de um estrangeiro".

Paulatinamente, por influência do cristianismo, por efeito da difusão de sentimento mais efetivo de simpatia e solidariedade, por maior compreensão e altruismo, modificou-se a situação jurídica e social do estrangeiro.

Começou a Revolução Francesa por suprimir aquêle droit d'aubaine, concedendo assim ao estrangeiro o direito de recolher herança ou legado deixados por nacionais.

Outras restrições foram sucessivamente desaparecendo, assegurando-lhe a Conferência Panamericana de 20 de fevereiro de 1928 o gôzo dos direitos civis essenciais, de sorte que, atualmente, por tôda a parte, o estrangeiro 
deixou de ser encarado como servo ou como inimigo, para tornar apenas criatura humana, merecedora, só por isso, de compreensão e de respeito.

Entretanto, como ainda subsistem várias restrições, que tendem novamente a dilatar-se, dando feição nova ao cosmopolitismo moderno, pareceu-nos adequado examinar quem é brasileiro e quem é estrangeiro perante a nova Constituição da República e quais as limitações que sôbre êstes pesam, em confronto com os nacionais. Êsse o objeto do presente estudo.

2. Como se sabe, a palavra nação engloba não só os indivíduos nacionais, que, num dado instante, se achem radicados no território de certo Estado.

$\mathrm{O}$ vocábulo abrange, igualmente, as gerações anteriores, com seu passado, suas lutas e tradições, sua cultura e seus valôres, acumulados e transmitidos às gerações atuais, como também às gerações futuras, que sucederão à presente.

Como disse Lomonaco, caros são a todos nós os pais, os filhos, o outro cônjuge, os parentes e os amigos, mas todos êsses afetos se concentram naquele pela pátria. Na frase de Rux, multiplicai a família e tereis a pátria. Sempre o mesmo plasma, a mesma substância nervosa, a mesma circulação sangüínea.

Sob êsse prisma, do ponto de vista sociológico, nacionalidade vem a ser um laço de pertinência à determinada nação. Sob essa luz, tanto mais nacional será a pessoa quanto maior se revele sua integração no seio da nação, considerada como complexo moral de elementos étnicos e espirituais, tais como a unidade de língua, de religião, de sentimentos de costumes, de consciência social e de leis.

Entrevisto o problema nesse ângulo, afirma o Professor José Horácio Meireles Teixeira, um filho de estrangeiro, ou mesmo um estrangeiro, naturalizado ou não, que viva em nosso país há muitos anos, completamente integrado na vida nacional, em nosso destino, nosso modo de 
ser e de sentir, poderá ser, na realidade, muito mais nacional, muito mais brasileiro, que o de inúmeras gerações, por qualquer circunstância não perfeitamente entrosado na coletividade nacional.

Sob o aspecto jurídico, todavia, que vem a ser nacionalidade? Ao que se afiança, tal palavra teria sido usada pela vez primeira por Madame de Stael.

Na definição de Pontes de Miranda, é um laço político-jurídico, de direito público interno, e que faz do indivíduo um elemento da dimensão pessoal do Estado.

Efetivamente, como é sabido, o Estado apresenta-se sob tríplice dimensão: material, que é o território, pessoal, que é o conjunto de seus habitantes, e jurídico, que é o poder supremo de autodeterminação política.

Se as nações são os indivíduos da humanidade, os indivíduos são o elemento pessoal da nação. Se o analisarmos mais detidamente, verificaremos que se compõe de nacionais e estrangeiros, além dos apátridas.

Não nos deteremos nestes últimos, que são aquêles que, por qualquer circunstância, vêm a perder a nacionalidade originária. Sem embargo dessa vicissitude, continuam naturalmente a ser considerados como sujeitos de direito em geral, por fôrça de sua natureza de entes humanos. No idioma alemão são assinalados pelo vocábulo heimathlos. Estão êles colocados ao abrigo da legislação de determinado país, sem a obrigação de suportar-lhe os encargos.

3. Para distinguir os nacionais e diferençá-los dos estrangeiros adotam as legislações contemporâneas dois sistemas, o do jus sanguinis e o do jus soli. Por êste último, que é de origem feudal, todo aquêle que venha a nascer no território de um Estado adquire a nacionalidade dêsse Estado. Pelo primeiro, o indivíduo tem, necessàriamente, a mesma nacionalidade de seus genitores, seja qual fôr o lugar de nascimento. 
A adoção exclusiva de um ou de outro critério, adverte Pontes de Mranda, conduz a situações injustas. O Estado que fizesse seus nacionais todos os filhos de nacionais, e só êsses, teria negado a indivíduos nascidos em seu território, penetrados dos hábitos nacionais, a qualidade de cidadãos nacionais, ao passo que a teria conferido a descendentes de nacionais, nascidos alhures, e já sem os hábitos, a educação, o amor $\mathrm{e}$ as preocupações de um nacional.

Por outro lado, a adoção exclusiva do jus soli importaria aceitação de que estrangeiros seriam os filhos de nacionais nascidos no exterior e nacionais os filhos de estrangeiros acidentalmente nascidos no Brasil.

Nosso país procurou sempre combinar ambos os critérios; mas, sendo nação nova, cujo elemento pessoal se nutriu principalmente da imigração, teria de outorgar primazia ao jus soli, sem que, com essa outorga, houvesse transformado o ente humano numa simples dependência do solo.

4. De acôrdo com a nova Constituição da República, promulgada a 24 de janeiro de 1967 e que entrou em vigor a 15 de março próximo passado, existem duas categorias de brasileiros: natos e naturalizados (nacionalidade originária e nacionalidade de aquisição).

Esclarece o inciso I do artigo 140, que, pràticamente, não alterou o estatuído pela Constituição de 1946, que são brasileiros natos: a) - os nascidos em território brasileiro, ainda que de pais estrangeiros, não estando êstes a serviço de seu país; b) — os nascidos fora do território nacional, de pai ou de mãe brasileiros, estando ambos ou qualquer dêles a serviço do Brasil; c) — os nascidos no estrangeiro, de pai ou de mãe brasileiros, não estando êstes a serviços do Brasil, desde que, registrados em repartição brasileira competente no exterior, ou não registrados, venham a residir no Brasil antes de atingir a maioridade. 
Neste caso, alcançada esta, deverão, dentro de quatro anos, optar pela nacionalidade brasileira.

Analisemos tais incisos. O primeiro caso é o mais comum de nacionalidade originária. Ao nascer o individuo já é brasileiro. Com a letra $a$, o legislador constituinte acolheu o principio do jus soli. Qualquer individuo que venha a nascer em território brasileiro é brasileiro, ainda que estrangeiro os pais dêle.

Por território brasileiro há de entender-se não apenas - que se localize materialmente dentro das nossas fronteiras, desde o Amapá até o Chuí, como também nossas águas territoriais, aeronaves e navios de guerra, em qualquer lugar em que se encontrem, bem assim aeronaves e navios mercantes, desde que em alto mar o fato do nascimento.

A contrario sensu, não serão brasileiros os que venham a nascer em aeronaves militares estrangeiras, ainda que sobrevoando território brasileiro, ou em navios de guerra, também estrangeiros, sulcando águas territoriais brasileiras, ou ancorados em pôrto brasileiro. Isso acontece porque aviões ou navios de guerra, onde quer que se encontrem, constituem prolongamento da nação a que pertencem, gozando, destarte, do privilégio da extraterritorialidade.

Como já se frisou, são brasileiros os que nascem em território brasileiro, ainda que de pais estrangeiros. Todavia, não terão nossa nacionalidade, se os pais aqui estiverem a serviço de seu próprio país.

Nesse caso, pôsto que nascido no Brasil, terá o filho a nacionalidade de seus pais. O princípio do jus soli será então afastado, tendo-se em conta a prestação do serviço público, por parte dos genitores, à pátria respectiva.

Entretanto, necessário se torna que os genitores aqui se encontrem a serviço de seu próprio país, porquanto se cá estiverem a serviço de outra nação, que não a de origem, o filho será brasileiro. 
Não é preciso que ambos os pais aqui estejam a serviço de sua pátria. Basta que um dêles esteja. É verdade que o texto constitucional emprega a palavra pais (no plural). Contudo, o emprêgo das palavras no plural constitui maneira comum de expressão por parte do legislador.

Se fortuito o nascimento em território brasileiro, estando os pais apenas de passagem, sem que se achem a serviço, não pode haver dúvida, o filho é brasileiro.

São igualmente brasileiros os nascidos fora do território nacional, de pai ou de mãe brasileiros, estando ambos ou qualquer dêles a serviço do Brasil.

Aplica-se, em tal hipótese, o princípio espiritual do jus sanguinis. A prestação de serviços no exterior determina a nacionalidade brasileira relativamente ao filho. Não é mister que ambos os genitores estejam a serviço do Brasil. Basta que um dêles esteja, pouco importando seja o pai ou a mãe.

A expressão a serviço do Brasil há de ser entendida em sentido amplo, de sorte a compreender igualmente o serviço dos Estados, dos Municípios e das autarquias (federais, estaduais e municipais).

Ainda que um dos genitores seja estrangeiro, se brasileiro o outro e se encontre no exterior a serviço do Brasil, o filho será brasileiro, pois é o serviço público brasileiro a causa direta do nascimento fora do país.

Em terceiro lugar, são ainda brasileiros natos os nascidos no estrangeiro, de pai ou mãe brasileiros, não estando èstes a serviço do Brasil, desde que, registrados ou não em repartição brasileira no exterior, venham a residir no Brasil antes de atingir a maioridade.

Em tal hipótese, o filho é brasileiro, sob uma condição, a de que opte pela nacionalidade brasileira dentro de quatro anos a contar do dia em que atinja a maioridade. A nacionalidade do pai ou da mãe apurar-se-á ao tempo do nascimento, mas a perda dela, por qualquer circunstância, não prejudicará o filho. 
A maioridade a que se refere o texto é a civil (21 anos) e não a política (18 anos), sem embargo da opinião contrária de Pontes DE MiRanda e de decisão no mesmo sentido do Tribunal Federal de Recursos, estampada na Revista de Direito Administrativo, vol. 55, pág. 256. Efetivamente, não fala o texto em maioridade política e por isso cumpre acolher interpretação mais liberal que amplia o prazo para a opção.

Tal opção constará de têrmo assinado pelo optante ou seu procurador no Registro Civil (Lei n. 818, de 18-9-49 artigo $\left.3 .^{\circ}\right)$. É competente para inscrição da opção o cartório da residência do optante, ou de seus pais (Decreto n. 4.857, de 9-11-1939, artigo $39, \S 2 .^{\circ}$ ).

Esclarece o artigo $4 .^{\circ}$ da Lei n. 818 que "o filho de brasileiro ou brasileira, nascido no estrangeiro e cujos pais ali não estejam a serviço do Brasil, poderá, após sua chegada ao Brasil, para nele residir, requerer ao juiz de Direito de seu domicílio, se transcreva, no Registro Civil, o têrmo de nascimento, fazendo-se constar dêste e das respectivas certidões que o mesmo só valerá como prova da nacionalidade brasileira até quatro anos depois de atingida a maioridade".

Se o filho não vem fixar-se no Brasil, antes de alcançada a maioridade, será estrangeiro, a menos que posteriormente se naturalize brasileiro. Mas, se se radica no Brasil e faz a opção no têrmo legal, terá esta fôrça retrooperante, como se o optante realmente houvesse nascido em solo pátrio. Como diz Luis Antonio de ANdrade, é brasileiro nato quem nasce brasileiro e não, como por equívoco se supõe, vulgarmente, quem nasce no Brasil. Se o brasileiro nascido no estrangeiro pode optar pela nacionalidade brasileira é porque, em princípio, já possui referida nacionalidade (Revista Forense, 154/82).

5. No inciso II, acrescenta o artigo 140 da Constituição Federal que são brasileiros naturalizados os que adquiriram a nacionalidade brasileira, nos têrmos do artigo 
69 ns. IV e V, da Constituição de 24 de fevereiro de 1891 (letra $a$ ).

São assim brasileiros os estrangeiros que, achando-se no Brasil a 15 de novembro de 1889, não declararam, dentro em seis meses depois de entrar em vigor a Constituição de 1891, o ânimo de conservar a nacionalidade de origem, bem como os estrangeiros, que possuissem bens imóveis no Brasil e fôssem casados com brasileira ou tivessem filhos brasileiros, contanto que residissem no Brasil, salvo se manifestassem a intenção de não mudar de nacionalidade.

$\mathrm{O}$ primeiro caso (inciso IV) corresponde à grande naturalização. $\mathrm{O}$ simples silêncio do estrangeiro aqui radicado, ao proclamar-se a República, bastou para que adquirisse a nacionalidade brasileira. Uma vez adquirida, meras manifestações posteriores não seriam aptas para arrebatar-lhe a nacionalidade adquirida.

Por outro lado, o inciso $\mathrm{V}$ exige o domínio de bens imóveis, não sendo suficiente a simples posse. $O$ verbo possuir, constante do texto, não se acha empregado em seu sentido técnico.

Prenchidos os requisitos legais, enumerados em ambas as alíneas, até 16 de julho de 1934, adquiriu o estrangeiro a nacionalidade brasileira, independente da expedição de título declaratório, a que se refere a Lei $n .^{\circ} 818$, de 18-91949 , artigo $6 .^{\circ}$, exigido apenas ad probationem e não $a d$ solemnitatem.

São ainda naturalizados, pela forma que a lei estabelecer (letra $b$ n. 1), os nascidos no estrangeiro, que hajam sido admitidos no Brasil durante os primeiros cinco anos de vida, radicados definitivamente no território nacional. Para preservar a nacionalidade brasileira, deverão manifestar-se por ela, inequivocamente, até dois anos após atingir a maioridade.

Trata-se de hipótese nova de aquisição da nacionalidade brasileira, subordinada ao concurso dos seguintes requisitos: a) ter vindo para o Brasil nos cinco primeiros 
anos de vida; b) - ter-se radicado definitivamente no país; c) - pronunciar-se de modo inequivoco pela nossa nacionalidade, até dois anos depois de atingida a maioridacle. A disposição, em última análise, limita-se a aplicar o velho adágio ubi bene ibi patria.

Por igual, são ainda naturalizados os nascidos no estrangeiro que, vindo residir no país antes de atingida a maioridade, façam curso superior em estabelecimento nacional e requeiram a nacionalidade até um ano depois da formatura (letra $b$ n. 2).

Cuida-se também de nova modalidade de naturalização e de que não cogitava a legislação anterior. A conjugação dos três elementos - fixação no país antes de atingida a maioridade, realização de curso superior em escola nacional e requerimento no prazo de um ano a contar da formatura -, evidenciam a total identificação do naturalizando com o país, sua completa integração em nosso meio, justificando-se, destarte, a concessão da nossa nacionalidade, como manifestação do jus allectionis.

Em terceiro lugar, são ainda naturalizados os que, por outro modo, adquirirem a nacionalidade brasileira, exigida aos portuguêses apenas residência por um ano ininterrupto, idoneidade moral e sanidade física (letra $b, \mathbf{n} .3$ ).

A outorga dessa naturalização constitui faculdade exclusiva do Presidente da República, em decreto referendado pelo Ministro da Justiça (Lei n. 818, artigo 7. $)$. Em alguns países, como a Holanda, a naturalização constitui ato do Poder Legislativo. Em outros, como a Argentina e alguns estados dos Estados Unidos, ela se inclui entre as atribuições do Poder Judiciário. No Brasil, todavia, é prerrogativa do Presidente da República.

As condições para obtenção do favor legal acham-se especificadas no artigo $80^{\circ}$ daquele diploma legal, que se refere, sucessivamente, à capacidade civil do naturalizando, segundo a lei brasileira, residência contínua no território nacional pelo prazo mínimo de cinco anos, imediatamente 
anteriores ao pedido de naturalização, ler e escrever a língua portuguêsa, levada em conta a condição do naturalizando, exercício de profissão ou posse de bens suficientes à manutenção própria e da família, bom procedimento, ausência de pronúncia ou condenação no Brasil, por crime cuja pena seja superior a um ano de prisão e sanidade física. Ainda que o naturalizando preencha todos os requisitos legais será lícito ao Presidente da República denegar-lhe a naturalização, que representa um benefício da lei, deferido por mera concessão do Estado, segundo o critério da autoridade competente.

Contudo, a tendência é no sentido de facilitar-lhe a obtenção. Não mais subsiste, nos dias atuais, o conceito antigo e feudal que considerava característica quase indelével na nacionalidade da pessoa. Pressurosos em favorecer a aquisição da nacionalidade, países novos, como o nosso, adotam orientação mais liberal, mais consentânea com a realidade, no intuito de incrementar a assimilação dos estrangeiros.

6. A Constituição assegura aos brasileiros e aos estrangeiros residentes no país a inviolabilidade dos direitos concernentes à vida, à liberdade, à segurança e à propriedade (artigo 150).

Igualmente, do ponto de vista do direito privado, do direito processual e do direito penal, inexiste qualquer diferença entre brasileiros e estrangeiros, situando-se todos, indistintamente, no mesmo pé de igualdade.

Relativamente aos direitos políticos, todavia, referentes à coparticipação do indivíduo no organismo social, sofrem os estrangeiros sensíveis restrições. Com efeito, de acôrdo com o $\S 1 .^{\circ}$ do artigo 140 são privativos de brasileiros natos os cargos de Presidente e Vice-Presidente da República, Ministro de Estado, Ministro do Supremo Tribunal Federal e do Tribunal Federal de Recursos, Senador, Deputado Federal, Governador e Vice-Governador de Estado e de Territórios e seus substitutos. Por igual, em 
conformidade com o artigo 142 da mesma Constituição os estrangeiros não podem ser eleitores.

Em meu Curso de Direito Civil, Parte Geral, tenho ensejo de apresentar extensa relação das numerosas limitações impostas não só a estrangeiros, como também a brasileiros naturalizados. A enumeração é tão vasta que não parece desarrazoada a opinião daqueles que como o desembargador Vieira Ferreira, sustentam achar-se revogado o artigo $30^{\circ}$ do Código Civil, segundo o qual "a lei não distingue entre nacionais e estrangeiros quanto à aquisição e ao gôzo dos direitos civis".

Em regra, os brasileiros natos têm a plenitude dos direitos civis e políticos. $O$ artigo $140, \S 22^{\circ}$, da Constituição Federal esclarece que "além das previstas nesta Constituição, nenhuma outra restrição se fará a brasileiro em virtude da condição de nascimento". Mas a distinção nacional-estrangeiro é fundamental e dela não se pode prescindir, tanto no campo do direito público, como do direito internacional.

7. Em conformidade com o artigo 141 da Constituição, perde a nacionalidade o brasileiro: I) - que, por naturalização voluntária, adquirir outra nacionalidade; II) que, sem licença do Presidente da República, aceitar comissão, emprêgo ou pensão de govêrno estrangeiro; III) - que, em virtude de sentença judicial, tiver cancelada a naturalização por exercer atividade contrária ao interêsse nacional.

Justifica-se a primeira hipótese. Elegendo voluntàriamente outra nacionalidade, renuncia o brasileiro a de origem. Entretanto, urge atender-se ao qualificativo: naturalização voluntária, porquanto se se cuida de naturalização imposta pela lei do lugar em que se encontre o brasileiro, conserva êste a nacionalidade de origem.

Na aceitação de comissão, emprêgo ou pensão de govêrno estrangeiro, mencionada na segunda alínea, não se compreendem, como adverte Pontes dE Miranda, prê- 
mios ou contribuições pro labore, bem como retribuições por serviços prestados à humanidade, às ciências e às artes, desde que não dependam do arbítrio do govêrno estrangeiro.

Mas, como a aceitação de comissão, emprêgo ou comissão implica vinculação a govêrno estrangeiro, a Constituição se mostra radical e comina a perda da nacionalidade brasileira, a menos que o interessado obtenha prèviamente licença do Presidente da República.

Em último lugar, perde também a nacionalidade brasileira o naturalizado que tenha cancelada a naturalização por decisão judicial, por ter exercido ou por exercer atividade considerada contrária ao interêsse nacional.

Como se trata de sentença constitutiva aquela que decreta o cancelamento da naturalização, segue-se que válidos serão todos os atos praticados pelo naturalizado enquanto a decisão não transita em julgado. Como pena que é, seus efeitos são puramente pessoais, não atingindo c outro cônjuge nem a prole.

8. Desejamos acrescentar ainda que compete à União legislar sôbre nacionalidade, cidadania e naturalização (Constituição Federal, artigo $8^{\circ}$, n. XVII, letra o) e essa competência é privativa ou exclusiva.

A cada nação cabe o direito de fixar soberanamente as regras sôbre aquisição e perda de nacionalidade, mediante a adoção dos critérios que lhe pareçam mais convenientes ou justos. Mas, como afirma Niboyet, um Estado não pode determinar senão seus próprios nacionais. Estado algum pode ter a pretensão de decidir quais sejam os nacionais de outros Éstados.

Por outro lado, nosso ordenamento jurídico repele o princípio da du'pla nacionalidade: duarum civitatum civis nos ter esse jure civili nemo potest. Tal a idéia que o direito romano acolheu e que o nosso sistema legal mantém. 
Observe-se ainda que se não pode contestar a quem quer que seja o direito de expatriar-se. É direito do indivíduo escolher uma nova pátria diversa da que lhe atribuíu o fato do nascimento ou da geração.

Cumpre ainda não se perder de vista o disposto na recente Lei n. 4.404, de 14-9-1964, já revogada, segundo a qual o menor estrangeiro residente no país, filho de pais estrangeiros naturalizados brasileiros e aqui domiciliados, é considerado brasileiro, para todos os efeitos (artigo $1 .^{\circ}$ ). Atingida a maioridade, deverá o interessado, para conservar a nacionalidade brasileira, optar, por ela, dentro de (quatro anos (artigo $2 .^{\circ}$ ).

9. Só nos resta abordar, a esta altura, o têma da cidadania, que, pela Constituição da República, é um direito (artigo 144, n. II, letra c). A qualidade de cidadão revestia-se, para os romanos, de extraordinário relêvo. 0 cives romanus sum representava, efetivamente, a síntese de enorme quantidade de direitos e prerrogativas.

Também hoje o direito de cidadania constitui insígnia que enaltece o individuo, pois o faz membro atuante da coletividade. Realmente, cidadania é a capacidade para exercer direitos políticos. Tem como pressuposto a nacionalidade.

Em nosso sistema positivo, cidadão e eleitor são palavras correspondentes ou sinônimas. Quem não é eleitor não é cidadão, pôsto tenha a nacionalidade brasileira. Nessas condições, quando a Constituição diz que qualquer cidadão será parte legítima para propor ação popular que vise a anular atos lesivos ao patrimônio de entidades públicas (artigo $150 \S 31$ ), está a aludir ao eleitor como tal alistado, na forma da lei. Será êsse alistamento que lhe confere os atributos defensivos ante a eventual exorbitância dos governantes.

10. É tempo de encerrar êste despretensioso trabalho escrito para Problemas Brasileiros e, ao fazê-lo, não logramos ocultar nosso sentimento de justo orgulho pelo trata- 
mento que o Brasil sempre soube dispensar aos estrangeiros.

Realmente, aqui, jamais medrou a xenofobia; aqui jamais se deu a repulsa do adventício ou o ódio ao forasteiro. Se, algumas vêzes, por circunstâncias fortuitas, germinou ou se exacerbou o sentimento nativista, jamais tal movimento implicou em menosprêzo em relação ao alienígena.

Por isso mesmo, à guisa de remate, desejamos trazer à recordação o que, certa feita, na Comédia Humana escreveu WiLliam Saroyan.

Há, nessa obra do notável escritor norte-americano, uma passagem em que divergem e discutem dois circunstantes. No auge da querela, um dêles, para ferir o outro, o chama de estrangeiro.

Dá-se então a advertência de um terceiro - um autêntico americano: nesta terra só é estrangeiro quem não hesita em lembrar a outrem sua origem.

Acredito seja essa a filosofia do povo brasileiro e que faz com que todo estrangeiro aqui se sinta como em sua própria casa, como em sua própria terra, sem diferença alguma a separá-lo dos nativos. É a filosofia da solidariedade e da compreensão, digna, pelo seu exemplo, de ser imitada e seguida. 